\title{
Crianças com Problemas de Comportamento Exteriorizado e a Dinâmica Familiar ${ }^{1}$
}

\author{
Maria Auxiliadora Dessen \\ Adriane Corrêa Szelbracikowski \\ Universidade de Brasília
}

\begin{abstract}
RESUMO
A literatura sobre crianças com problemas de comportamento exteriorizado tem enfatizado a necessidade de focalizar o desenvolvimento cognitivo, o estresse parental e os padrões de relação familiar para melhor compreender o seu ajustamento e desenvolvimento. Este estudo visa descrever os tipos de famílias de crianças com comportamentos exteriorizados, destacando o perfil cognitivo das crianças, o estresse parental e a qualidade das relações familiares. Foram selecionadas 14 crianças préescolares morando com ambos os pais biológicos, ou com a mãe e o padrasto ou com apenas um genitor. Foram aplicados testes de avaliação cognitiva às crianças e, aos genitores, uma escala de estresse parental, questionário e entrevista semi-estruturada. Os dados mostram que o perfil cognitivo das crianças é caracterizado por um raciocínio geral abaixo da sua idade cronológica e que a dinâmica do relacionamento familiar difere em função do tipo de família e entre pais e mães, sendo os padrastos mais estressados que os genitores biológicos. Os resultados sugerem que há necessidade de investigar melhor a origem e a evolução dos comportamentos exteriorizados na perspectiva do curso de vida, considerando os tipos de famílias.
\end{abstract}

Palavras-chave: relações familiares; problemas de comportamento exteriorizado; estresse parental.

\section{ABSTRACT \\ Children's Externalizing Behavior Problems and the Family Functioning}

Available literature about children externalizing behavior problems has emphasized the necessity of research focusing on cognitive development, parental stress, and patterns of family relationships for better understanding of their adjustment and development. The aim of this study is to identify the types of families of children who present externalizing behavior, highlighting the children's cognitive profile, parental stress, and the quality of family relationships. Fourteen children who were living with their biological parents, a mother and stepfather, or just one parent were selected to participate in this study. Data on cognitive evaluation was collected in regard to these children and a scale, a questionnaire, and a semi-structured interview were administered to their parents. The results show that the children's cognitive profile is characterized by low general reasoning compared to their biological age. The dynamic of family relationships differs according to the type of family; that with stepfathers being more stressed than those with biological fathers and mothers. This suggests that it is necessary to implement research to investigate the origins and developmental trajectories of externalizing behaviors and the need to adopt a life-span approach and consideration of the types of families.

Keywords: family relationships; externalizing behavior problems; parental stress.

Os comportamentos exteriorizados têm sido descritos como uma variedade de respostas de descumprimento de regras sociais e de problemas de conduta, incluindo agressão física e verbal, roubo, mentira, rebeldia, delinqüência, crueldade física e atos criminosos (Rothbaum \& Weisz, 1994; Van der Valk, Verhulst, Stroet \& Boomsma, 1998).

Os últimos anos têm registrado um aumento crescente do interesse dos pesquisadores por crianças muito jovens que apresentam sinais precoces de problemas de comportamento ou risco psicopatológico, que dificilmente seriam detectados antes do seu ingresso na escola (Hinshaw, 1992). Tais estudos são o ponto de partida para compreendermos como as ações, pensamentos e emoções envolvidos nos comportamentos exteriorizados estão inter-relacionados, ao longo do ciclo de vida. Por exemplo, crianças que apresentam índices elevados de problemas de comportamento exteriorizado no início da vida estão mais propensas a intensificar as mentiras, brigas e lutas ainda na infância, assim como crueldade com animais, vandalismo, comportamentos agressivos e criminosos na adolescência (Hann \& Borek, 2001).

As relações entre crianças com problemas de comportamento e seus genitores são caracterizadas, em sua maioria, por práticas parentais como coerção, 
disciplina inconsistente, grande hostilidade, indiferença, negatividade, restrição emocional, pouca afetividade e apoio, punição e parentalidade abusiva (Edens, Cavell \& Hughes, 1999). Esses genitores têm sido caracterizados como disciplinadores inadequados e inconsistentes por serem, algumas vezes, rudes e punitivos e, outras vezes, totalmente permissivos. Alguns deles promovem o comportamento anti-social de suas crianças sem intenção, usando, além de práticas disciplinares inadequadas, expressões de raiva em relação à criança. Tais comportamentos podem produzir efeitos danosos à auto-regulação das emoções e/ou promover o reforçamento de comportamentos agressivos e disruptivos (Kim, Hetherington \& Reiss, 1999; Wu e cols., 2002).

Quando os pais não conseguem distinguir entre os seus papéis e os da criança, a família torna-se um caos freqüente, com uma possibilidade de diminuição da sua capacidade de desempenho em outros aspectos da parentalidade (Cavell, 2000; Coie \& Dodge, 1998). E é neste contexto que a criação e as práticas de socialização dos filhos podem se tornar fonte de estresse para os genitores, afetando toda a dinâmica de funcionamento familiar, particularmente o desenvolvimento e a manutenção dos problemas de comportamento exteriorizado. $\mathrm{O}$ estresse influencia as práticas parentais disciplinares, tais como dar ordens à criança e reforçar o seu comportamento aversivo, e favorece as trocas coercivas que promovem e aumentam diretamente o comportamento agressivo e de oposição da criança (Kazdin \& Whitley, 2003).

Portanto, este estudo tem como objetivo principal identificar as similaridades e diferenças entre os tipos de famílias de crianças com comportamento exteriorizado, destacando (a) o perfil cognitivo das crianças, (b) a qualidade das relações familiares, particularmente entre os genitores/padrastos e sua criança e (c) os índices de estresse dos genitores/padrastos decorrentes de suas relações parentais. Para alcançar tais objetivos, adotamos uma abordagem multimetodológica, recorrendo a questionários, testes, escalas, entrevistas e um roteiro de observação do ambiente físico.

\section{MÉTODO}

\section{As crianças e suas famílias}

As crianças pré-escolares com problemas de comportamento exteriorizado $(\mathrm{N}=14)$ e suas respectivas famílias foram recrutadas na cidade de Brasília-DF e seu entorno, sendo três do sexo feminino e 11 do sexo masculino, com idade média de 5 anos, freqüentando instituições públicas de ensino, por ocasião da coleta de dados. As crianças foram indicadas por suas professoras, que responderam um questionário sobre o seu Perfil Socioafetivo - PSA (LaFreniere, Dumas,
Capuano \& Dubeau, 1992), classificando-as como apresentando problemas de comportamento exteriorizado. As famílias dessas crianças foram agrupadas em três tipos: Tipo 1 - criança morando com ambos os genitores biológicos $(n=7)$; Tipo 2 - criança morando com a mãe biológica e o padrasto $(n=3)$; Tipo 3 criança morando apenas com um genitor, o pai $(n=1)$ ou a mãe $(n=3)$.

A renda média das famílias era de $\mathrm{R} \$ 1.002,00$ (um mil e dois reais), correspondendo a 7,4 salários mínimos $^{2}$, variando de R\$130,00 $(n=1)$ até $\mathrm{R} \$ 3.500,00(n=1)$. A idade média das mães era de 30 anos, dos pais de 34 anos e 5 meses e dos padrastos de 45 anos. Nas famílias do Tipo 1, o tempo de convivência dos cônjuges variava de 6 a 21 anos e nas do Tipo 2, de 2 a 5 anos. Quanto ao nível de escolaridade dos genitores, a maioria das mães e pais possuía o ensino fundamental incompleto (M: $n=8 ; \mathrm{P}: n=4)$ e o ensino médio completo (M: $n=3$; $\mathrm{P}: n=2$ ); dos padrastos, um era semi-analfabeto e os outros dois haviam concluído o ensino fundamental. As ocupações exercidas por mães, pais e padrastos eram diversificadas: vendedor(a), copeira, empregada doméstica, auxiliar de enfermagem, motorista, mestre de obras, bombeiro, eletricista, professor etc. Das mães, três não trabalhavam fora de casa e três estavam desempregadas por ocasião da coleta de dados; dos pais/padrastos, apenas um estava desempregado.

\section{Procedimentos para a Coleta de Dados}

A coleta de dados foi efetuada em duas etapas, na escola e na casa das famílias. A avaliação cognitiva das crianças foi realizada na escola e constou da aplicação de dois testes de inteligência: 'Raven: Matrizes Progressivas Coloridas' (Angelini, Alves, Custódio, Duarte \& Duarte, 1999) e 'Colúmbia' (Alves, Duarte \& Duarte, 1993). Foi aplicado, também, um teste de prontidão para a alfabetização: 'Teste do Pirulito' (Chew, 1981). Na casa das famílias, as mães responderam um questionário sobre informações sociodemográficas e caracterização da família (Dessen, 1999) e os genitores e padrastos participaram, separadamente, de uma entrevista semi-estruturada (Dessen \& Bigras, 2000) e da aplicação de uma escala de estresse parental (Abidin, 1995). Essa escala, denominada de Índice de Estresse Parental-PSI, composta por 36 itens, subdivididos em três subescalas: 'sofrimento parental', 'interações disfuncionais entre genitor-criança' e 'criança difícil', foi apenas traduzida para o português ${ }^{3}$. A coleta de dados na casa da família incluiu, também, a observação das condições de moradia (Dessen, 2000), que consistia no preenchimento de um roteiro imediatamente após o término da visita. 
Este roteiro contém itens referentes às condições físicas (número de cômodos), materiais (móveis e aparelhos domésticos/eletrônicos), de higiene (água, esgoto e banheiro) e de limpeza da moradia.

\section{RESULTADOS}

\section{Quem são as crianças?}

O perfil cognitivo das crianças é caracterizado por um raciocínio geral (Colúmbia) abaixo da sua idade cronológica, por uma capacidade intelectual média (Raven) e por uma realização bem sucedida em cerca

\section{Tipo 1 田 Tipo 2 四 Tipo 3}

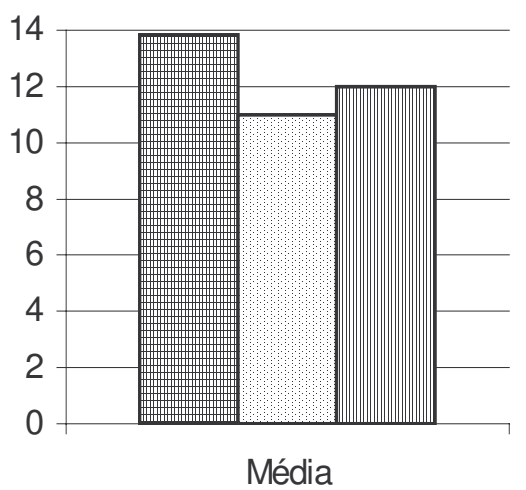

Figura 1: Média dos escores brutos das crianças no Teste Raven, por tipo de família.

No que se refere às expectativas a respeito do rendimento acadêmico das crianças, a maioria dos genitores/padrastos acredita que o rendimento é igual ao das outras crianças $(n=16)$ e que ela concluirá o ensino superior $(n=18)$. Todos acreditam que as crianças devem freqüentar a escola e atribuem a responsabilidade pelo rendimento acadêmico da criança à professora, embora, para alguns deles $(n=5)$, esta responsabilidade é tanto da professora como da criança e/ou dos genitores.

Tanto as mães quanto os pais descrevem as suas crianças como agitadas (M: 3; P: 2), alegres (M: 4; P: 2), nervosas (M: 2; P: 1), teimosas (M: 2; P: 2) e afetivas (M: 2; P: 2). Mas, para os padrastos, as crianças são obedientes, nervosas e agressivas. As famílias diferem na percepção de seus filhos. Para as famílias do Tipo 1, as crianças são alegres, agitadas e teimosas; para as do Tipo 2, elas são obedientes, agressivas e nervosas; e, finalmente, para as famílias do Tipo 3, as crianças são agressivas.

As características e comportamentos adequados das crianças, mencionados pelos genitores/padrastos, são: alegre, bem humorado, afetivo, carinhoso, amoroso (aspectos emocionais e de personalidade); prestativo, comportado, obediente, respeitador (aspectos de $60 \%$ das questões de prontidão para a alfabetização. As crianças, em todos os tipos de famílias, apresentam um desempenho abaixo da idade cronológica em termos de raciocínio geral, embora tenham diferido quanto à capacidade intelectual (Tipo 1: média; Tipo 2: baixa; Tipo 3: abaixo da média). Em relação à prontidão para a alfabetização, as crianças das famílias do Tipo 1 obtiveram os escores mais altos, seguidas das crianças do Tipo 3 e do Tipo 2. As Figuras 1 e 2 mostram, respectivamente, as médias de capacidade intelectual e de prontidão para alfabetização, por tipo de família.
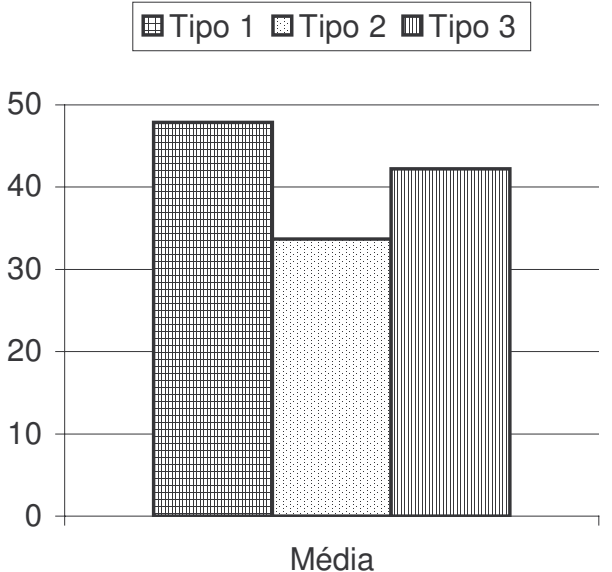

Figura 2: Média dos escores brutos no teste de prontidão para alfabetização, por tipo de família.

sociais); inteligente, esperto, observador (aspectos cognitivos). As características e comportamentos inadequados são: impulsivo, nervoso, ciumento, teimoso, agitado, mimado, preguiçoso, rebelde, mau-humorado (aspectos emocionais e de personalidade); briguento, birrento, desobediente, respondão (aspectos sociais); dificuldades em realizar as tarefas escolares (aspectos cognitivos). Enquanto os pais ressaltam apenas aspectos emocionais e de personalidade no que tange às características/comportamentos adequados e inadequados, os padrastos apontam somente aspectos sociais. Já as mães destacam aspectos sociais como adequados e os emocionais e de personalidade como inadequados.

Segundo o relato das famílias, o desenvolvimento motor e da linguagem de suas crianças foi normal, embora 4 famílias do Tipo 1 tenham relatado que o desenvolvimento de seus filhos foi precoce. Quanto ao desenvolvimento social, a maioria dos genitores $(n=22)$ relatou que as crianças tinham facilidade para 'fazer amigos', padrão que se manteve para todos os tipos de famílias.

\section{Quem São as Famílias das Crianças?}

O modo de vida das famílias compreende aspectos variados tais como hábitos de higiene, cuidados dispensados aos filhos, afazeres domésticos, rede de 
apoio e contato social. Os hábitos de higiene mencionados no questionário (respondido por um dos genitores) foram: tomar banho $(n=12)$, escovar os dentes $(n=12)$, limpar a casa $(n=9)$ e outros (pentear os cabelos, lavar os ouvidos, cortar as unhas etc). Todas as famílias do Tipo 1 e a maioria das famílias dos Tipos 2 e 3 relataram como principais hábitos de higiene 'tomar banho' e 'escovar os dentes'. A limpeza da casa também foi relatada pelas famílias do Tipo 1 $(n=5)$, do Tipo $2(n=2)$ e do Tipo $3(n=2)$.
Em relação às atribuições domésticas, as mães são as principais responsáveis pelas atividades relativas aos cuidados dos filhos e pela execução das tarefas de casa. Levar as crianças para atividades de lazer é a atividade mais executada pelos pais, enquanto, para os padrastos, é a de fazer compras. A participação dos pais/padrastos, em todos os tipos de famílias, é menor que a das mães, tanto em relação aos cuidados dispensados às crianças como na execução de tarefas domésticas, conforme mostra a Tabela 1.

Tabela 1: Participação dos membros familiares nas tarefas domésticas e de cuidados dispensados aos filhos, por tipo de família

\begin{tabular}{|c|c|c|c|c|c|c|c|c|c|c|c|c|c|c|c|}
\hline \multirow[t]{2}{*}{ Famílias } & \multicolumn{5}{|c|}{ TIPO 01} & \multicolumn{5}{|c|}{ TIPO 02} & \multicolumn{5}{|c|}{ TIPO 03} \\
\hline & $M$ & $P$ & $A$ & $S$ & 0 & M & $\mathrm{Pd}$ & $A$ & S & 0 & M & $P$ & $A$ & S & 0 \\
\hline Cuidados dispensados aos filhos & $\mathrm{Fr}$ & $\mathrm{Fr}$ & $\mathrm{Fr}$ & $\mathrm{Fr}$ & $\mathrm{Fr}$ & $\mathrm{Fr}$ & $\mathrm{Fr}$ & $\mathrm{Fr}$ & $\mathrm{Fr}$ & $\mathrm{Fr}$ & $\mathrm{Fr}$ & $\mathrm{Fr}$ & $\mathrm{Fr}$ & $\mathrm{Fr}$ & $\mathrm{Fr}$ \\
\hline Dar comida/banho & 5 & 1 & - & 1 & - & 3 & - & - & - & - & 2 & - & 1 & 2 & - \\
\hline Levar/Trazer da escola & 7 & 3 & - & - & - & 3 & - & - & - & - & 1 & - & - & - & 3 \\
\hline Orientar dever & 7 & 2 & - & - & - & 3 & - & - & - & - & 3 & - & - & - & 1 \\
\hline Levar atividade lazer & 6 & 7 & - & - & - & 3 & 1 & - & - & - & 3 & 1 & - & - & - \\
\hline Colocar para dormir & 7 & 5 & - & - & - & 3 & 1 & - & - & - & 2 & - & - & - & 2 \\
\hline \multicolumn{16}{|l|}{ Tarefas Domésticas } \\
\hline Cozinhar & 7 & 1 & - & - & - & 3 & - & - & - & - & 3 & - & 1 & - & - \\
\hline Lavar/passar & 6 & 1 & - & - & 1 & 3 & - & - & - & - & 3 & - & 1 & - & - \\
\hline Fazer compras & 7 & 3 & - & - & - & 3 & 2 & - & - & - & 2 & - & 2 & - & - \\
\hline Orientar empregada & 3 & - & - & - & - & - & - & - & - & - & - & - & - & - & - \\
\hline
\end{tabular}

Nota. As categorias M, P, Pd, A, S e O representam, respectivamente, 'Mãe', 'Pai', 'Padrasto', 'Avós', 'Sozinho' e 'Outros'. Esta última categoria inclui tios maternos e paternos, empregada e vizinhos. Os genitores relataram a participação de mais de uma pessoa nas tarefas domésticas.

A rede social de apoio inclui os membros familiares, amigos, vizinhos, profissionais e instituições; mas, são os membros da própria família as principais fontes de apoio $(n=13)$. As famílias dos Tipos 1,2 e 3 mencionaram, respectivamente, as seguintes fontes de apoio: familiares $(n=7 ; n=3 ; n=4)$, não familiares $(n=5 ; n=1 ; n=1)$, instituições $(n=1 ; n=2 ; n=3)$ e profissionais $(n=2 ; n=1 ; n=1)$.

No contato social, as atividades de lazer preferidas são as visitas a parentes e amigos, passeios no parque, ir à igreja, ficar em casa, ir ao shopping e a festas de aniversários. Em geral, a família toda participa das atividades: a mãe $(n=14)$, o pai ou padrasto $(n=9)$, os irmãos $(n=11)$ e outras pessoas $(n=1)$. As principais atividades de lazer, nas famílias do Tipo 1, são: visitas a parentes e amigos $(n=5)$ e passeios no parque $(n=3)$, com a participação de todos os membros familiares. Nas famílias do Tipo 2, as atividades sociais são variadas: ir a festas de aniversários $(n=1)$, ao parque $(n=1)$ e à igreja $(n=1)$, além de outras, tendo a companhia da mãe. Nas famílias do Tipo 3, ir ao shopping $(n=2)$, ao parque $(n=1)$ e à igreja $(n=1)$, com o genitor responsável pela criança, foram as atividades predominantes.

Os principais eventos ocorridos na vida das crianças e de suas famílias, tais como mudança de escola, repetência, agressão à professora e aos coleguinhas, separação/divórcio dos genitores, brigas entre o casal, uso de álcool e/ou drogas e envolvimento com a polícia, são listados na Tabela 2.

Tabela 2: Eventos ocorridos com a criança e suas famílias, por tipo de família

\begin{tabular}{lccccc}
\hline EVENTOS OCORRIDOS & TIPO 1 & TIPO 2 & TIPO 3 & TOTAL \\
\cline { 2 - 5 } COM A CRIANÇA & $\mathrm{Fr}$ & $\mathrm{Fr}$ & $\mathrm{Fr}$ & $\mathrm{Fr}$ \\
\hline Mudança de escola & 2 & 1 & 1 & 4 \\
Repetência & 1 & - & - & 1
\end{tabular}




\begin{tabular}{lllll} 
Suspensão & - & - & 1 & 1 \\
Agressão à professora & 1 & 1 & 1 & 3 \\
Agressão aos colegas & 4 & 2 & 3 & 9 \\
COM A FAMílıIA & 2 & - & 1 & 3 \\
Arrumar emprego & 2 & 1 & 1 & 4 \\
Perda de emprego & 3 & 1 & 3 & 7 \\
Problemas financeiros & 1 & - & 1 & 2 \\
Nascimento de filho & 2 & 1 & 2 & 5 \\
Problemas de saúde & 4 & 1 & 2 & 7 \\
Brigas entre os pais & - & 1 & 1 & 2 \\
Separação/Divórcio & 2 & 1 & 3 & 6 \\
Consumo de álcool/drogas & - & 1 & 2 & 3 \\
Problemas com a polícia & & & & \\
\hline
\end{tabular}

É interessante observar que, em todos os tipos de família, houve o relato de perda de emprego e problemas financeiros; já as mães das famílias dos Tipos 1 e 3 começaram a trabalhar fora de casa. No que se refere às condições de moradia das famílias, são as do Tipo 1 que apresentam as melhores condições de moradia, higiene e limpeza, enquanto as famílias do Tipo 2 vivem em condições mais precárias que as demais.

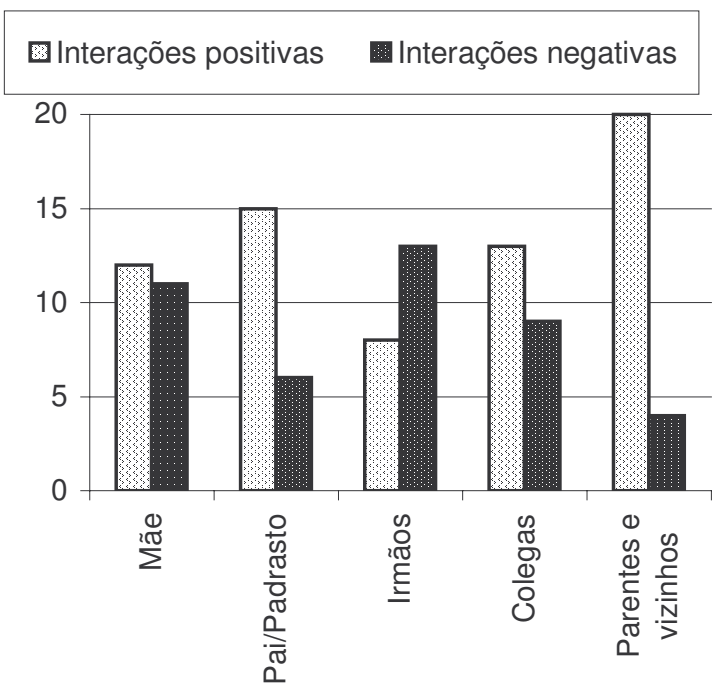

Figura 3: Interações positivas e negativas das crianças.

O envolvimento do pai na vida familiar é total e do padrasto parcial, com os genitores das famílias dos Tipos 1 e 2 (incluindo os padrastos) expressando satisfação com este envolvimento. No entanto, a maioria das mães do Tipo 3 estava insatisfeita porque os pais

\section{Como é a Dinâmica das Relações Familiares?}

Os estilos de relacionamento das crianças foram classificados em positivos e negativos. Segundo o relato dos entrevistados $(\mathrm{N}=24)$, a maioria das interações positivas das crianças é com os parentes e vizinhos e com o pai/padrasto e a maioria das interações negativas é com os irmãos e com as mães (ver Figura 3). As interações são mais positivas nas famílias do Tipo 1 e mais negativas nas do Tipo 3. A Figura 4 mostra o percentual de interações positivas e negativas, para cada tipo de família, separadamente.

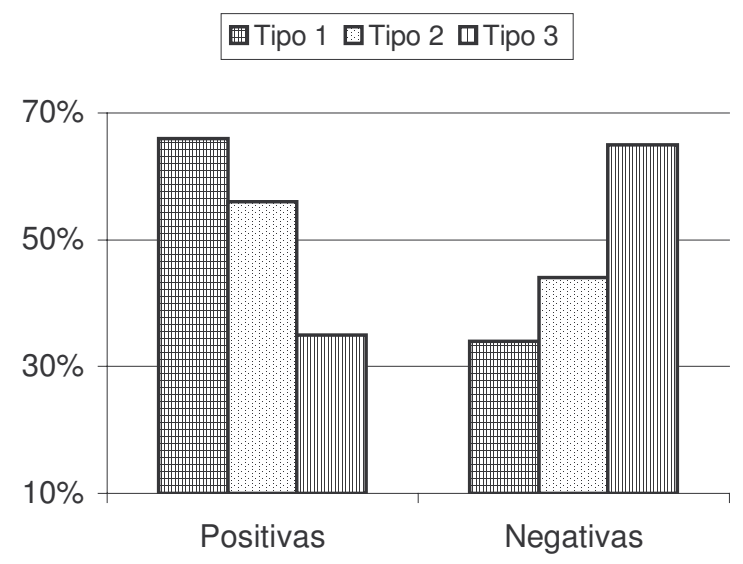

Figura 4: Interações positivas e negativas das crianças, para cada tipo de família, separadamente.

não participavam da vida familiar. A predominância da autoridade exercida sobre a criança, nas famílias dos Tipos 1 e 2, é compartilhada pela díade mãepai/padrasto e nas famílias do Tipo 3 é individualizada, exercida pela mãe ou pela avó. 
A maioria das famílias estava feliz com a vida familiar, com a criança alvo e os outros filhos e, também, com o trabalho; nas famílias dos Tipos 1 e 2, esta satisfação era extensiva à boa convivência entre os cônjuges. Por exemplo, quanto à vida em família: "Ah, eu me sinto feliz... ah, porque como eu já falei... hoje eu tenho uma família, um lar, tenho como educar meus filho. É isso" (Mãe da C7, família Tipo 2); quanto à criança alvo: "Eu me sinto feliz, eu amo muito ele [a criança]...” (Mãe da $\mathrm{C} 1$, família Tipo 1); quanto à convivência conjugal: "É boa, né, tens uns probleminha assim que todo mundo tem, mas tá muito bom. Eu acho que também se não tiver um probleminha aqui, acolá, fica aquela coisa monótona, aí não dá pra vive não, na monotonia, não. Pra diferencia o dia-a-dia" (Mãe da C1, família Tipo 1).

Os valores mais importantes transmitidos pelas famílias referem-se à 'Conformidade', que compreende as dimensões de respeitabilidade, obediência, responsabilidade, educação informal e valores morais. Por exemplo: “... ah, sempre respeita os colega, né.
E as tia... as pessoas mais velha. É isso que eu ensino pra ele sempre: o respeito em primeiro lugar (mãe da C7, família Tipo 2). As estratégias de socialização mais utilizadas são 'Diálogo' (famílias do Tipo 1) e 'Punição Física' (famílias dos Tipos 2 e 3) e 'Verbal' (família do Tipo 2). 'Elogios' e 'Incentivos' são estratégias empregadas por todas as famílias.

\section{O Estresse Parental}

O índice de estresse parental foi calculado somando-se as respostas das mães, pais e padrastos, separadamente, obtendo-se o escore bruto para cada um deles, o que corresponde ao estresse experienciado. $\mathrm{O}$ índice de estresse nas famílias deste estudo $(X=96,5)$ corresponde a 2,5 pontos acima do mínimo obtido na amostra canadense (Bigras, Venet \& Normandeau, 2002), que varia de 94 (mínimo) a 117 (máximo). A Figura 5 apresenta, respectivamente, os escores globais do nível de estresse das mães e pais e padrastos, por tipo de família.

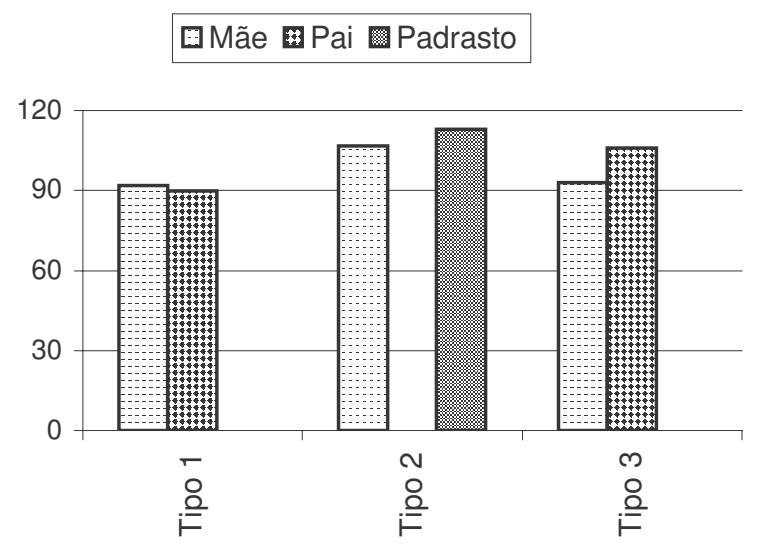

Figura 5: Média do índice total de estresse parental, por tipo de família, com identificação dos genitores. Em uma das famílias do tipo 3, o genitor responsável pela criança era o pai.

O estresse parental é distribuído de forma diferenciada, de acordo com três subescalas: 'sofrimento parental', 'interações disfuncionais' e 'criança difícil'. As famílias do Tipo 2 são as mais estressadas nas três subescalas e no índice de estresse global. A Tabela 3 mostra os escores médios nas subescalas, por tipo de família.

Tabela 3: Escores médios do índice de estresse parental, por tipo de família

\begin{tabular}{lcccc}
\hline \multicolumn{1}{c}{ Estresse Parental } & $\begin{array}{c}\text { Variação na } \\
\text { amostra canadense }\end{array}$ & Tipo 1 & Tipo 2 & Tipo 3 \\
\hline Estresse Global & $94-117$ & 90,8 & 109,8 & 96,2 \\
Subescala 'sofrimento parental' & $33-46$ & 27,8 & 35 & 27,7 \\
Subescala 'interações disfuncionais' & $28-36$ & 29 & 36,5 & 33 \\
Subescala 'criança difícil' & $37-46$ & 34 & 38,3 & 38 \\
\hline
\end{tabular}




\section{DISCUSSÃO}

Adotamos, nesse trabalho, o conceito mais abrangente de 'comportamento exteriorizado' em substituição ao conceito de 'comportamento agressivo', uma vez que este termo é mais apropriado quando o foco de análise não se restringe apenas a comportamentos agressivos. A maioria das crianças com problemas de comportamento exteriorizado que participaram deste estudo são do sexo masculino, o que corrobora os dados da literatura, que mostra que os meninos apresentam mais comportamentos exteriorizados que as meninas (Bigras \& Dessen, 2002; Rothbaum \& Weisz, 1994; Walker, Irving \& Berthelsen, 2002). Portanto, a classificação feita pelas professoras, nas salas de aula das instituições de ensino do Distrito Federal e entorno, respondendo à escala de Perfil Socioafetivo, foi apropriada.

Quanto à coleta de dados, a maioria dos membros familiares foi incluída como informantes: a mãe, o pai, o padrasto e a criança; a entrevista semi-estruturada, o questionário sociodemográfico e as escalas foram administrados visando à complementaridade das informações, o que possibilitou uma visão comparativa e abrangente do funcionamento das famílias. Os instrumentos da avaliação cognitiva (Raven: Matrizes Progressivas Coloridas e Colúmbia) são padronizados e comumente aplicados à população brasileira, exceto o teste de prontidão para a alfabetização (Teste do Pirulito), que é adequado a diferentes contextos culturais (Chew, 1981).

A avaliação cognitiva mostra que a metade das crianças do nosso estudo foi classificada com capacidade intelectual média e cinco como estando abaixo da média, o que é coerente com os dados a respeito da relação entre comportamento agressivo e nível intelectual baixo (Cavell, 2000). A prontidão para a alfabetização, que depende dos recursos do ambiente em que a criança está inserida, foi mais alta para as crianças de famílias do Tipo 1 que para as dos Tipos 2 e 3 , padrão que se manteve em todos os testes de avaliação cognitiva. Esses resultados sugerem explicações diferentes. Nas famílias do Tipo 2, o motivo principal parece ser o fato de as crianças pertencerem a um ambiente com recursos precários e de baixa estimulação associado a um período de adaptação e de conflitos conjugais. Já nas famílias do Tipo 3, a ausência de um dos genitores parece desequilibrar o sistema familiar, reduzindo as interações e, conseqüentemente, a possibilidade de um ambiente mais rico para o desenvolvimento da capacidade intelectual da criança.
Considerando as peculiaridades da dinâmica de relações em famílias recasadas e com ausência de um dos genitores, não é de se estranhar que as crianças tenham apresentado escores baixos em rendimento intelectual e prontidão para alfabetização. A literatura é conclusiva a respeito do fato de que problemas familiares, particularmente de relacionamento conjugal, acarretam prejuízos para os cônjuges e influenciam negativamente o desenvolvimento da criança, especialmente no que tange à baixa performance acadêmica (Erel \& Burman, 1995; Gottman, 1998). As famílias do Tipo 1 são as que vivem em melhores condições de funcionamento, na medida em que ambos os genitores podem compartilhar as tarefas domésticas. Apesar disso, as mães continuam sendo as principais responsáveis pelas atividades realizadas no contexto do lar e, os pais/padrastos, por aquelas realizadas fora de casa, como levar os filhos para atividades de lazer e fazer compras, o que corrobora os dados da literatura sobre o envolvimento de mães e pais nas atividades domésticas (Dessen \& Braz, 2000; Kaloustian, 1998).

No entanto, a autoridade exercida sobre a criança é compartilhada pelo casal quando a estrutura familiar é composta por um casal, seja a mãe e o pai biológico ou a mãe e o padrasto; mas, nas famílias do Tipo 3, com apenas um genitor, a autoridade é individualizada e assumida pela mãe. Esses arranjos familiares refletem os modelos tradicionais de funcionamento da família (ver, por exemplo, Kaloustian, 1998; Romanelli, 1998), em que os papéis de gênero são delimitados e a autoridade é compartilhada entre o casal. Tais arranjos precisam ser investigados no contexto brasileiro, bem como os modos pelos quais as famílias estão socializando as crianças para assumirem o papel de pai, no futuro. Dessen e Lewis (1998) sugerem que as famílias brasileiras, particularmente as de baixa renda, podem não estar preparando as suas crianças para assumirem o papel de pai 'moderno'.

Os valores que os genitores/padrastos acham importantes na criação e educação de filhos, e que procuram transmitir às suas crianças pré-escolares, são aqueles relativos à conformidade, ou seja, educação, boas maneiras e respeito, o que corrobora os dados de Tudge e cols. (1999) a respeito de famílias de classe social baixa. No entanto, as estratégias de socialização mais empregadas pelos genitores/padrastos diferem de acordo com o tipo de família. As famílias do Tipo 1 usam mais o 'Diálogo' com o intuito de corrigir os erros dos filhos; as do Tipo 2, a 'Punição Física' e, as do tipo 3, a 'Punição Verbal'. E são as práticas de punição empregadas pelas famílias dos tipos 2 e 3 que 
podem estar estimulando a manifestação de comportamentos exteriorizados pela criança, conforme ressaltado por Kim e cols. (1999) e Wu e cols. (2002).

Considerando que o estresse parental influencia as práticas disciplinares e estas, por sua vez, promovem e aumentam o comportamento agressivo e de oposicão da criança (Kadzin \& Whitley, 2003), a validação da escala PSI para a população brasileira trará contribuições valiosas para a compreensão da dinâmica das relações em famílias de crianças pré-escolares com problemas de comportamento exteriorizado. Mas, o fato de que os genitores deste estudo tenham obtido escores mais baixos de estresse que os canadenses não significa que suas crianças apresentem menos problemas de comportamento, e, conseqüentemente menos estresse. Pode ser que os genitores brasileiros tenham mais tolerância e/ou não percebam os problemas de comportamento como sendo difíceis.

Em relação ao desenvolvimento e às características das crianças, constatou-se que as famílias do Tipo 1 não percebiam as suas crianças como agressivas; apenas como agitadas, impulsivas e alegres. Talvez essas famílias tenham concepções diferentes daquelas da professora a respeito de ser 'agressivo' ou as crianças, de fato, não apresentam tais comportamentos no ambiente de casa, restringindo-os apenas à escola. Esta última hipótese parece mais plausível, pois dos eventos normativos e não normativos ocorridos com a criança, a agressão aos colegas foi o evento mais relatado pelos genitores, o que confirma a classificação das crianças efetuada pelas professoras. As interações negativas com os irmãos têm sido apontadas como algo predominante na idade pré-escolar (Tremblay, 2000), podendo o irmão mais velho constituir um modelo a ser imitado pela criança mais nova. Como a família é a base de socialização da criança, esta, em contato com um irmão agressivo, pode manifestar tais comportamentos, estendendo-os aos seus relacionamentos com os pares, na escola (Kim e cols., 1999). As interações com os irmãos foram percebidas como positivas somente nas famílias do Tipo 2 , talvez devido à necessidade de apoio e de formar alianças entre eles, compensando a forte aliança formada entre a mãe e seu novo parceiro (Hetherington, 1993).

A criança pode também aprender comportamentos agressivos na escola e no convívio com pares agressivos, em geral. Se levarmos em conta os dados desse estudo, em que as professoras classificaram todas as crianças como agressivas e/ou irritadas, mas os genitores, em geral, não as percebiam como tal, podemos supor que a escola constitui, para essas crianças, um ambiente propício para o desenvolvimento de comportamentos agressivos, pelo menos mais do que o ambiente de casa. Sugerimos que pesquisas futuras investiguem mais detalhadamente as associações entre as interações negativas entre os irmãos e a agressividade manifesta em casa e na escola, com companheiros, particularmente no contexto cultural brasileiro, em que a agressão e a violência fazem parte do cotidiano das escolas públicas de periferia.

É preciso, também, investigar melhor a associação entre desenvolvimento cognitivo, dinâmica das relações familiares e estresse parental, levando em conta os tipos de famílias que possuem crianças com problemas de comportamento exteriorizado, pois os padrões de relação familiar variam de acordo com o tipo de família (Bray \& Berger, 1993; Hetherington, 1993). Acreditamos que o trabalho ora apresentado, embora simples em sua metodologia e pouco pretensioso em seus objetivos, indique novas possibilidades de investigação sobre problemas de comportamento exteriorizado e estimule a análise de padrões de relações familiares, por tipo de família, para melhor compreender a origem e evolução de tais comportamentos, assim como subsidiar a prática clínica e escolar.

\section{REFERÊNCIAS}

Abidin, R. R. (1995). Parenting stress index. Odessa, FL: Psychological Assessment Resources.

Alves, I. C. B.; Duarte, J. L. \& Duarte, W. (1993). Escala de maturidade mental Colúmbia. São Paulo: Casa do Psicólogo.

Angelini, A. L.; Alves, I. C. B.; Custódio, E. M.; Duarte, W. F. \& Duarte, J. L. M. (1999). Matrizes progressivas coloridas. São Paulo: CETEPP.

Bigras, M. \& Dessen, M. A. (2002). Social competence in Brazilian preschoolers. Early Education \& Development, 13, 139-151.

Bigras, M.; Venet, M. \& Normandeau, S. (2002, agosto). The relation between cognitive and socioaffetive predictors of academic performance at the ends of first grade. Trabalho apresentado no $17^{\text {th }}$ Meeting of International Society for Study of Behavioral Development, Ottawa, Canadá.

Bray, J. H. \& Berger, H. (1993). Developmental issues in stepfamilies research project. Family relationships and parent-child interactions. Journal of Family Psychology, 7, 76-90.

Cavell, T. A. (2000). Working with parents of aggressive children: a practitioner's guide. Washington, DC: American Psychological Association.

Chew, A. L. (1981). The lollipop test: a diagnostic screening test of school readiness. Atlanta, GA: Humanics Limited.

Coie, J. D. \& Dodge, K. A. (1998). Aggression and antisocial behavior. Em W. Damon \& N. Eisenberg (Orgs.), Handbook of child psychology: social, emotional, and personality development (pp. 779-840). Toronto: Wiley.

Dessen, M. A. (1999). Questionário sociodemográfico da família. Manuscrito não publicado, Laboratório de Desenvolvimento Familiar, Instituto de Psicologia da Universidade de Brasília, Brasília.

Dessen, M. A. (2000). Roteiro de observação - condições de moradia. Manuscrito não publicado, Laboratório de Desenvolvimento Familiar, Instituto de Psicologia da Universidade de Brasília, Brasília. 
Dessen, M. A. \& Bigras, M. (2000). As crianças pré-escolares com problemas de comportamento e suas famílias: identificação de fatores de risco. Relatório de Pesquisa (Processo n. ${ }^{\circ}$ 523059/96-5). Brasília: CNPq.

Dessen, M. A. \& Braz, M. P. (2000). Rede social de apoio durante transições familiares decorrentes do nascimento de filhos. $P s i$ cologia: Teoria e Pesquisa, 16, 221-231.

Dessen, M. A. \& Lewis, C. (1998). Como estudar a família e o “pai”. Cadernos de Psicologia e Educação Paidéia, 8, 105-121.

Edens, J.; Cavell, T. \& Hughes, J. (1999). The self-systems of aggressive children: A cluster-analytic investigation. Journal of Child Psychology and Psychiatry, 40, 441-453.

Erel, O. \& Burman, B. (1995). Interrelatedness of marital relations and parent-child relations: A meta-analytic review. Psychological Bulletin, 118, 108-132.

Gottman, J. M. (1998). Psychology and the study of marital processes. Annual Review of Psychology, 49, 169-197.

Hann, D. M. \& Borek, N. (2001). Taking stock of risk factors for child/youth externalizing behavior problems. Washington, DC: National Institute of Mental Health.

Hetherington, E. M. (1993). An overview of the Virginia longitudinal study of divorce and remarriage with a focus on early adolescence. Journal of Family Psychology, 7, 39-56.

Hinshaw, S. P. (1992). Externalizing behavior problems and academic underachievement in childhood and adolescence: causal relationships and underlying mechanism. Psychological Bulletin, 111, 127-155.

Kaloustian, S. M. (Org.). (1998). Família brasileira: a base de tudo. São Paulo: Cortez Editora.

Kazdin, A. E. \& Whitley, M. K. (2003). Treatment of parental stress to enhance therapeutic change among children referred for aggressive and antisocial behavior. Journal of Consulting and Clinical Psychology, 71, 504-515.

Kim, J.; Hetherington, E. \& Reiss, D. (1999). Associations among family relationships, antisocial peers and adolescents' externalizing behaviors: Gender and family type differences. Child Development, 70, 1209-1230.
LaFreniere, P. J.; Dumas, J. E.; Capuano, F. \& Dubeau, D. (1992). Development and validation of preschool socioaffective profile. Psychological Assessment, 4, 442-450.

Romanelli, G. (1998). O relacionamento entre pais e filhos em famílias de camadas médias. Cadernos de Psicologia e Educação Paidéia, 8, 123-136.

Rothbaum, F. \& Weisz, J. R. (1994). Parental caregiving and child externalizing behavior nonclinical samples: A meta-analysis. Psychological Bulletin, 116, 55-74.

Tremblay, R. E. (2000). The development of aggressive behaviour during childhood: What have we learned in the past century? International Journal of Behavioral Development, 24, 129-141.

Tudge, J.; Hogan, D.; Lee, S.; Tammeveski, M. M.; Kulakova, N.; Snezhkova, I. \& Putnam, S. (1999). Cultural heterogeneity: Parental values and beliefs and their preschoolers' activities in the United States, South Korea, Russia, and Estonia. Em A. Göncü (Org.), Children's engagement in the world: sociocultural perspectives (pp. 62-96). London: Cambridge University Press.

Valk, J. C. van der; Verhulst, F. C.; Stroet, T. M. \& Boomsma, D. I. (1998). Quantitative genetic analysis of internalizing and externalizing problems in a large sample of 3-year-old twins. Twin Research, 1, 25-33.

Walker, S.; Irving, K. \& Berthelsen, D. (2002). Gender influences on preschool childrens' social problem-solving strategies. The Journal of Genetic Psychology, 163, 197-209.

Wu, P.; Robinson, C. C.; Yang, C.; Hart, C. H.; Olsen, S. F.; Porter, C. L.; Jin, S.; Wo, J. \& Wu, X. (2002). Similarities and differences in mother's parenting of preschoolers in China and the United States. International Journal of Behavioral Development, 26, 481-491.

Enviado: 10/10/2004 Revisado: 10/11/2004 Aceito: $15 / 11 / 2004$

\section{Notas:}

${ }^{1}$ Este estudo é parte de um projeto de pesquisa intitulado "Crianças Pré-escolares com Problemas de Comportamento e suas Famílias: Identificação de Fatores de Risco". As autoras agradecem o apoio recebido do CNPq e da CAPES.

${ }^{2} \mathrm{O}$ salário mínimo vigente era de $\mathrm{R} \$ 136,00$.

${ }^{3}$ Esta escala encontra-se em processo de validação para a população brasileira.

\section{Sobre as autoras:}

Maria Auxiliadora Dessen: Doutora em Psicologia pela Universidade de São Paulo, com pós-doutoramento pela Universidade de Lancaster, Inglaterra, e pelo Instituto Max Planck para o Desenvolvimento Humano, Berlim, Alemanha. Professora do Instituto de Psicologia da Universidade de Brasília-UnB.

Endereço para correspondência: Universidade de Brasília-UnB; Instituto de Psicologia/PED; Laboratório de Desenvolvimento Familiar; Campus Universitário Darcy Ribeiro; Brasília-DF; CEP: 70.910-900 - Endereço Eletrônico: dessen@unb.br.

Adriane Corrêa Szelbracikowski: Mestra em Psicologia pela Universidade de Brasília-UnB e pesquisadora do Laboratório de Desenvolvimento Familiar do Instituto de Psicologia da UnB. 